\title{
Debates Neoliberales en 1938. El Coloquio Lippmann ${ }^{1}$
}

\section{Neoliberal Debates in 1938. The Lippmann Colloquium \\ Debates neoliberais em 1938. 0 Colóquio Lippmann}

\author{
Adán Salinas Araya ${ }^{2}$ \\ Recibido: 21/11/2016 - Aceptado: 02/12/2016
}

\begin{abstract}
Resumen:
Se tratan algunas de las discusiones vertidas en el coloquio Lippmann de 1938, evento que puede considerarse con los datos actuales como la escena inaugural del neoliberalismo. Se muestra tanto la heterogeneidad de dos grupos de pensadores que marcarán posteriormente la línea alemana y norteamericana de pensadores neoliberales. Al mismo tiempo se muestran algunas de sus coincidencias principales en torno a una idea de democracia para el mercado.
\end{abstract}

Palabras clave: neoliberalismo - Lippmann - Mises - Rougier - Hayek ordoliberalismo

\begin{abstract}
:
This work addresses some of the discussions that took place in the Lippmann Colloquium of 1938, an event that can be considered with the current data as the inaugural scene of neoliberalism. It shows both the heterogeneity
\end{abstract}

1 El presente artículo está basado en una conferencia en la UCSH en enero de 2016, con motivo del lanzamiento de la revista Hermenéutica Intercultural. Se ha adaptado su escritura para la publicación, aunque mantiene la dinámica propia de una exposición abierta, de modo que algunas de las explicaciones iniciales pueden resultar conocidas para un lector entendido, aunque necesarias en la exposición.

2 Chileno, Doctor en Filosofía por la Universidad Complutense de Madrid. Magíster en Filosofía por la Universidad de Chile. Máster en Estudios Avanzados en Filosofía por la Universidad Complutense de Madrid. Licenciado en Educación y Profesor de Filosofía por la Universidad Católica Silva Henríquez. Actualmente realiza una investigación postdoctoral en el departamento de Historia de la Filosofía en la Universidad Complutense de Madrid. Este artículo es parte del proyecto postdoctoral "Seguridad y regulación en la fase neoliberal del biopoder". N: 74150012 CONICYT, Chile. Contacto: adan.salinas@cenaltes.cl 
of two groups of thinkers who will later mark the German and American line of neoliberal thinkers and at the same time, it addresses some of their main coincidences around an idea of democracy for the market.

Keywords: neoliberalism - Lippmann - Mises - Rougier - Hayek - ordoliberalism

Resumo:

Este artigo trata de alguma das discussões lançadas no colóquio Lippmann 1938, evento que pode ser visto com os dados atuais como a cena inaugural do neoliberalismo. Mostra-se tanto a heterogeneidade de dois grupos de pensadores neoliberais que vão marcar posteriormente a linha alemã e americana de pensadores neoliberais. Ao mesmo tempo, se mostram algumas de suas coincidências principais em torno de uma ideia de democracia para o mercado.

Palavras-chave: neoliberalismo - Lippmann - Mises - Rougier - Hayek ordoliberalismo.

\section{Importancia del coloquio Lippmann en una genealogía crítica del neoliberalismo}

Quisiera detenerme en algunos aspectos del Coloquio Lippmann, realizado en París en 1938. No es un evento muy conocido, aunque pienso que tiene cierta relevancia para un proyecto más amplio como el de realizar una genealogía crítica del neoliberalismo; que es, al mismo tiempo, un asunto clave y una tarea en desarrollo. Por eso como primer punto intentaré mostrar cuál sería la importancia de este coloquio en relación al estado actual de esta posible genealogía crítica.

La categoría neoliberalismo es actualmente muy usada y ha ido creciendo en importancia, especialmente en las voces críticas al conjunto de políticas implementadas a finales de los 70 y principios de los 80 en los regímenes de Reagan, Thatcher y Pinochet, y posteriormente a lo que se conoció, en la década de los 90 , como el "consenso de Washington" ${ }^{3}$. En cierto sentido este consenso de Washington ha

3 Ver Williamson, John. «What Washington Means by Policy Reform». En Williamson, John (ed). Latin American Adjustment: How Much Has Happened? Institute for 
servido como imagen central y definición práctica del neoliberalismo en los discursos más habituales y en la opinión pública. Por eso voy a señalar algunas cosas previas sobre este "consenso de Washington".

En primer lugar este consenso consiste en la enumeración de unas cuantas medidas y su importancia radica en que las medidas ahí enumeradas sirvieron como una especie de imagen del neoliberalismo de los ochenta, con la novedad política que implicaba en esa época la implementación de las reformas neoliberales. Lo segundo, aunque esto ha servido de imagen programática para describir el neoliberalismo de dicha época, y hasta cierto punto de definición operativa del neoliberalismo en general, no era -en realidad- un programa propuesto por Williamson, sino que pretendía ser una síntesis empírica de lo que estaba pasando en las reformas realizadas hasta 1989. De hecho, Williamson explica que intentaba enumerar los elementos que según su opinión generarían consenso entre los expertos de los organismos de Washington, sobre la política económica en América Latina, y no tanto ofrecer un manifiesto neoliberal ${ }^{4}$. Esto conecta con lo tercero que creo importante enfatizar porque muchas veces se suele pasar de largo. Esta síntesis de Williamson, se refiere a Latinoamérica, a las reformas realizadas en América Latina hasta 1989. Williamson lo explica del siguiente modo en un texto posterior: "La razón que me llevó a compilar el consenso de Washington no era otra que documentar o informar sobre los cambios de actitudes políticas que se estaban produciendo en América Latina, cambios que, por lo menos en apariencia, no eran percibidos desde Washington en ese momento" ${ }^{\prime 5}$. De modo que la imagen del neoliberalismo que se extrae de este consenso, corresponde a la aplicación relativamente inmodificada de la teoría

International Economics, Washington, 1990. También Kuczynski, Pedro. «Explicando el contexto». en Kuczynski, Pedro; Williamson John (eds.), Después del Consenso de Washington. Relanzando el crecimiento y las reformas en América Latina. Lima, Universidad Peruana de Ciencias Aplicadas, 2003.

4 Williamson, John. «Revisión del consenso de Washington». En Emerij, Luis; Núñez Del Arco, José. El desarrollo económico y social en los albores del siglo XXI. BID, Washington, 1998, p. 50.

5 Williamson, John. «Revisión del consenso de Washington», p. 51. 
neoliberal norteamericana que está influyendo en los programas de reformas políticas en Latinoamérica, incluso sin el relativo conocimiento de los expertos de Washington, según la opinión de Williamson. Lo que importa es que este consenso refleja entonces un particular estado de estas reformas, una suerte de desplazamiento y desajuste de inicio ${ }^{6}$; pues ninguno de los principios en los que se fundamentan estas reformas fueron pensados para la realidad social o económica latinoamericana, sino que como veremos más adelante, comenzaron a desarrollarse en el periodo de entreguerras en Europa. El resumen de las medidas descritas por Williamson tiene 10 características ${ }^{7}$ :

1 Disciplina presupuestaria (rechazo al endeudamiento y a las medidas contracíclicas). 2 Cambios en las prioridades del gasto público (los subsidios se eliminan y se enfoca el gasto en educación y sanidad). 3 Reforma fiscal (bajar la recaudación y mantener un mínimo de recaudación integral no proporcional). 4 Tipos de cambio (liberalización y bajas tasas, lo que resultó en la práctica una contradicción). 5 tipo de cambio real competitivo (tendiente a la liberalización completa, pero con matices). 6 Liberalización comercial (se promueven las importaciones y se eliminan protecciones a la industria nacional). 7 Apertura a la inversión extranjera directa. 8 Privatizaciones de empresas públicas, bienes y servicios de uso público. 9 Desregulación de la actividad empresarial y financiera. 10 Aseguramiento de los derechos de propiedad.

6 Es interesante revisar en paralelo las apreciaciones y objeciones de Williamson en la Conferencia de 1997, ver Williamson, John. «Revisión del consenso de Washington» y las que comentaré aquí en el Coloquio de 1938, pues se trata básicamente de los mismos aspectos programáticos y los mismos reparos de "política social" expresados en el coloquio. Aunque hayan pasado exactamente 50 años, la segunda guerra mundial, el desplome de los socialismos de inspiración soviética, y sobre todo que se trate de una región del mundo completamente diferente, con otra masa demográfica, relaciones de recursos, tipos de economías según sector, procesos de industrialización, desarrollos tecnológicos, entre muchos otros elementos diferenciadores. El desajuste corresponde a la sobre abstracción de la teoría económico-política neoliberal que considera un programa casi sin diferencias, aplicable para cualquier región del mundo después de 50 años. Este desajuste resalta el aspecto no científico, sino ideológico que predomina en la concepción neoliberal de la economía.

7 Williamson, John. «What Washington Means by Policy Reform». También de manera más resumida, Williamson, John. «Revisión del consenso de Washington», pp. 64-65. 
Como es posible apreciar a partir de la enumeración anterior, este "consenso de Washington", aunque no fuese propuesto inicialmente como programa, llegó a ser la guía que inspira el conjunto de medidas político-sociales que posteriormente servirían como línea de acción a los organismos reunidos en torno a Washington (Banco Mundial, Fondo Monetario Internacional, tesoro norteamericano) en un primer círculo, pero que además sirve de círculo de contagio a una serie de otros organismos internacionales que serán especialmente influyentes en las políticas internacionales concretas.

En buena medida hasta el día de hoy, cuando en los discursos críticos se habla de neoliberalismo, se remite a esta imagen anterior. Se trata de un uso general del término neoliberalismo, que corresponde a una manera de identificar un cierto grupo de políticas económicas: Reagan, el thatcherismo y el friedmanpinochetismo ${ }^{8}$ que posteriormente se transformarían en "consenso" general. Estos serían los referentes concretos iniciales y en segundo lugar la ola expansiva de programas del FMI, que usaron estas ideas como guía programática

8 Estos tres hitos ya se han asentado en la literatura clave. "¿De qué modo se consumó la neoliberalización, y quién la implementó? La respuesta, en países como Chile y Argentina en la década de 1970 fue tan simple como súbita, brutal y segura, esto es, mediante un golpe militar respaldado por las clases altas tradicionales (así como también por el gobierno estadounidense), seguido de una represión salvaje de todos los vínculos de solidaridad instaurados en el seno de la fuerza de trabajo y de los movimientos sociales urbanos que tanto habían amenazado su poder. Pero la revolución neoliberal que suele atribuirse a Thatcher y a Reagan, después de 1979 tuvo que consumarse a través de medios democráticos. Para que se produjera un giro de tal magnitud fue necesaria la previa construcción del consentimiento político a lo largo de un espectro lo bastante amplio de la población como para ganar las elecciones". Harvey, David. A brief history of neoliberalism. Oxford University Press, New York, 2005, p. 39. Hay que recordar que para Harvey también es clave el proceso chino desde las reformas de Deng Xiaoping en 1978, aunque la bibliografía en general no toma en cuenta el proceso chino y se abstiene en general de hablar de neoliberalismo para el caso chino.

9 Sólo a modo de ejemplo el FMI concedió más de 140 préstamos internacionales para la implementación de reformas inspiradas en estas medidas para la educación superior. Ver Salinas Araya, Adán. Vidas precarias y Ciclo Vital. Escrituras aneconómicas. Vol. V, 2014. Éste es precisamente el objetivo que Casilda Béjar, un autor cercano a la política neoliberal, le otorga precisamente al consenso de Washington "(...) nace en 1989 en el llamado «Consenso de Washington», donde se trató de formular un 


\section{A partir de esta idea, o imagen inicial, se han elevado los primeros trabajos críticos que pretenden analizar y describir esta corriente; me parece que dos ejemplos importantes por su sistematicidad y tam- bién por su influencia son los trabajos de Perry Anderson ${ }^{10}$ y David Harvey ${ }^{11}$; estos trabajos incluyen muchos aportes, pero al mismo}

listado de medidas de política económica para orientar a los gobiernos de países en desarrollo y a los organismos internacionales (Fondo Monetario Internacional, Banco Mundial y Banco Interamericano de Desarrollo (FMI, BM y BID)) a la hora de valorar los avances en materia económica de los primeros al pedir ayuda a los segundos". Casilda Béjar, Ramón. América Latina. y el Consenso de Washington. Boletín Económico de ICE $n^{\circ} 2803$ del 26 de abril al 2 de mayo de 2004, p. 19.

10 Anderson fija el momento fundacional del neoliberalismo en el libro de Von Hayek "Camino de servidumbre" de 1944, en que se identifica el proyecto de una economía acompañada de política social, lo que podríamos considerar el supuesto socialdemócrata, con una finalidad similar a la del nazismo. Este libro daría pie a la formación de la Société du Mont-Pèlerin en 1947. Ver Anderson, Perry. «Historia y lecciones de neoliberalismo» Hourtart, François; Polet, François. El otro Davos: globalización de resistencias y de luchas. Plaza y Valdés, Madrid, 2001, pp. 13-30.

11 Harvey hace hincapié en el proceso "destructivo" que realiza el neoliberalismo, sus estrategias de desposesión de lo público y lo común, aunque presta menos atención a los procesos creativos o la producción de nuevas formas de mercantilización, dispositivos de circulación, etc. Tiene la ventaja de que extiende el análisis político a la década de 1970, con la crisis de Nueva York y el proceso de especulación territorial en México. Ver Harvey, David. A brief history of neoliberalism. Oxford University Press, New York, 2005. El acento de Harvey es insistir en los elementos que hacen del neoliberalismo una extensión del desarrollo capitalista más clásico, y por tanto su propio análisis es una extensión del análisis marxista más clásico. Por ejemplo respecto al problema de la ideología y la dominación de clase aclara: "En mi interpretación, el neoliberalismo ha sido un proyecto de clase camuflado bajo una proteica retórica sobre la libertad individual, el albedrío, la responsabilidad personal, la privatización y el libre mercado. Pero esa retórica no era sino un medio para la restauración y consolidación del poder de clase, y en este sentido, el proyecto neoliberal ha sido todo un éxito" Harvey, David. «ils This Really the End of Neoliberalism?». En Counterpounch March, 13, 2009. Disponible en http://www.counterpunch.org/2009/03/13/is-this-really-theend-of-neoliberalism/. Por otra parte la "acumulación por desposesión", que es la principal estrategia de acumulación neoliberal descrita por Harvey, es asumida como una forma renovada de la expropiación que da pie a la acumulación originaria: "Sin embargo, el logro más sustantivo de la neoliberalización ha consistido en redistribuir, no en generar, la riqueza y la renta. En un trabajo previo, he proporcionado un análisis de los principales mecanismos que han sido utilizados para conseguir esto, bajo el título de «acumulación por desposesión». Esta expresión alude a la continuación y a la proliferación de prácticas de acumulación que Marx había considerado como «originaria» o «primitiva» durante el ascenso del capitalismo". Harvey, David. A bief history of neoliberalism. p. 159. En este sentido el análisis de Harvey tiene un límite 
tiempo, hoy se muestran como un primer acercamiento necesario de complementar; pues la reconstrucción de estas problemáticas o por decirlo así la genealogía crítica del neoliberalismo es más compleja de lo que había parecido en estas primeras investigaciones. Si seguimos a Anderson habría que establecer el punto de inicio de la doctrina neoliberal en el libro de Hayek Camino de servidumbre ${ }^{12}$ como texto fundacional del neoliberalismo en 1944 y el hito orgánico que consolida este inicio teórico sería la fundación de la Société du Mont-Pèlerin en 1947. Esto es congruente si asumimos el consenso de Washington como el elemento definitorio del neoliberalismo, o, lo que es similar, si asumimos la escuela de Chicago como el referente único e ideotípico del neoliberalismo. Pero aquí pretendo decir algo diferente. Las medidas del consenso de Washington, me parece que son el epifenómeno, lo más destacable de un tipo particular de neoliberalismo, o de la escuela austro-norteamericana, o también de una postura neoclásica. Aunque ésta no es la única posición neoliberal. Veo, y en esto sigo a Foucault y a otros ${ }^{13}$, que la imagen de lo que hoy

evidente, pues aprecia novedades ilusorias en el neoliberalismo, que en realidad son extensión, proyección, renovación de elementos del capitalismo más clásico. Por supuesto esta hipótesis puede resultar cierta, pero es al mismo tiempo demasiado arriesgada y demasiado cómoda. Puesto que no hay elementos substancialmente nuevos, no es necesario alejarse de la teoría que ya se maneja, no es necesario dar pasos fuera; pero es al mismo tiempo muy arriesgado, pues si la hipótesis resulta falsa, es decir, si resulta que hay elementos substancialmente nuevos, la renuncia teórica y política a detenerse en ellos es demasiado grande. Por supuesto estoy de acuerdo con Harvey en la vigencia del análisis de Marx y tengo el mayor respeto por los trabajos y las propuestas de Harvey que me parecen del mayor nivel. Pero al mismo tiempo pienso que es una exigencia teórica, al menos para mí, no sólo intentar decir lo que el presente tiene en común con los esquemas ya conocidos y el pasado, sino también lo que tiene de diferente y singular. En este sentido creo que un análisis crítico del neoliberalismo queda mejor afinado en la medida que apunta a las singularidades del mismo.

12 Ver Hayek, Friedrich. Camino de servidumbre. Madrid: Alianza, 1985.

13 Ver Foucault, Michel. Naissance de la biopolitique. Cours au Collège de France 1979-1980. Seuil/Gallimard, Paris, 2004. También Laval, Christian; Dardot, Pierre. La nouvelle raison du monde. La Découverte, Paris, 2010. Denord, François. «Aux origines de néolibéralisme en France; Louis Rougier et le colloque Walter Lippmann de 1938». En Le Mouvement social, 2001, № 195, pp. 9-34. Y el que me parece en la actualidad la descripción más acabada y que mejor refleja el estado del arte actual: Mirowski, Philip; Plehwe, Dieter. The Road From Mont Pèlerin. Harvard University 
llamamos neoliberalismo debe ser ampliada más allá del consenso de Washington, e incluso más allá de la sociedad de Mont Pèlerin, para integrar las posiciones del ordoliberalismo, más moderadas que las norteamericanas, pero igualmente neoliberales. El hecho de que la imagen dominante del neoliberalismo corresponda al consenso de Washington y su expansión, no es algo ilógico, por el contrario es muy explicable; pues desde el punto de vista político la concreción de estas reformas y su difusión por los organismos internacionales, las hacen especialmente identificables y próximas. Sin embargo los estudios actuales, o incluso la difusión de estudios antiguos -como el curso de Foucault de 1979 antes citado- han mostrado que en realidad hay una mayor heterogeneidad de posturas y también que la historia del neoliberalismo es más antigua e intrincada. A modo de ejemplo es muy interesante un artículo de Bernard Walpen el 2005, en el que propone narrar una historia breve del neoliberalismo en 11 puntos 0 grandes hitos ${ }^{14}$. En esa lista las reformas de Pinochet inspiradas por Friedman recién aparecen en el número 9, Thatcher y Reagan en el número 10, y la extensión del neoliberalismo como pensamiento hegemónico global después de 1989, sería el punto 11. Los primeros 8 puntos son en general desconocidos, quizás con la excepción de la sociedad de Mont Pelèrin.

Esta genealogía se ha hecho por partes, en algunas ocasiones con más profundidad y acierto. En mi opinión la revisión actual más completa, es The Road From Mont Pèlerin de Mirowski y Plehwe. En las líneas que siguen, pretendo aportar a esa reconstrucción en una perspectiva crítico-genealógica con algunos apuntes sobre el coloquio Walter Lippmann celebrado en 1938 y que parece ser -hasta el momento- un hito fundacional de eso que hoy llamamos neoliberalismo. Aunque en el esquema de Walpen ocupa el puesto tercero. Y, por otra parte,

Press, Cambridge-London, 2009. Mis análisis anteriores en esta línea pueden verse especialmente en Salinas, Adán. «El hombre empresa como proyecto ético-político. Lecturas de Michel Foucault". En Hermenéutica intercultural. 18-19, 2010, pp. 95-139, y Salinas, Adán. La semántica biopolítica. Cenaltes Ediciones, Viña del Mar, 2014.

14 Walpen, Bernhard. «Auf dem Pilgerberg oder: Dialektik der Freiheit. Eine kurze Geschichte des Neoliberalismus» En Denknetz Jahrbuch 2005, pp. 210-218. 
ya hay antecedentes en la década del 20 y del 30, concretamente a través del trabajo de la revista Ordo a partir de 1936, como señala Foucault ${ }^{15}$, y del libro Liberalismus de Von Mises en $1927^{16}$, donde se apela por la formación de un nuevo liberalismo -Neuen Liberalismus-, expresión traducida al inglés como neoliberalism ${ }^{17}$. Walpen señala que ya en 1921 es posible rastrear un programa auténticamente neoliberal en el libro Gammal och ny ekonomisk liberalism del economista sueco Eli F. Heckscher ${ }^{18}$.

Louis Baudin, un autor neoliberal que participó en el Coloquio Lippmann, señala -en 1953- que el término neoliberalismo fue precisamente acuñado en dicho congreso ${ }^{19}$ por Louis Rougier, el principal

15 Ver Foucault, Michel. Naissance de la biopolitique, p. 107 ss.

16 Mises, Ludwig von. Liberalismus. Jena, Verlag, 1927. Hay traducción castellana en 1975 bajo el título Liberalismo y editada por Unión Editorial, reeditada por Planeta en 1994.

17 Ver la traducción al ingles de Ralph Raico en Mises, Ludwig von. Liberalism. Van Nostran, Princeton, 1978. Enrique Ghersi, un autor neoliberal peruano, proporciona el dato anterior, además Ghersi hace remontar esta apelación de Von Mises por un nuevo Liberalismo al libro anterior, comúnmente mencionado coloquialmente como Socialismo "en Socialismo, que es de 1922, habla [Von Mises] también acerca de la diferencia entre el viejo liberalismo (älteren Liberalismus) y el nuevo liberalismo (neuen Liberalismus), pero tampoco usa expresamente la palabra "neoliberalismo" para describir a este último". Ghersi, Enrique. «El mito del neoliberalismo». Estudios Públicos, 95 (invierno 2004), p. 295. Aunque Ghersi aclara que estas expresiones de Von Mises son algo diferente a lo que se entiende en la actualidad por neoliberalismo. La retórica reaccionaria de Ghersi bien vale otra cita: "(...) si bien es posible rastrear el término «neoliberalismo» hasta Von Mises, el sentido que estas alusiones precursoras tuvieron no fue siempre el mismo. En Liberalismo se usó para designar a los socialistas encubiertos y otros enemigos de la libertad; en Socialismo, para designar al liberalismo después de la teoría subjetiva del valor". Ghersi, Enrique. «El mito del neoliberalismo», p. 297. Al revisar el texto de Von Mises no he encointrado la expresión a la que alude Ghersi, neuen Liberalismus, aunque no se puede descartar que haya pasajes en los que el texto se refiera a un nuevo liberalismo con otra expresión similar. Ver el original en Mises, Ludwig von. Die Gemeinwirtschaft. Untersuchungen über den Sozialismus. Verlag von Gustav Fischer, Jena, 1922. Disponible en http://docs.mises.de/Mises/ Mises_Gemeinwirtschaft.pdf

18 Walpen, Bernhard. «Auf dem Pilgerberg oder: Dialektik der Freiheit. Eine kurze Geschichte des Neoliberalismus», p. 210.

19 Ver Baudin, Louis. L'aube d'un nouveau libéralisme. Librairie de Médicis, Paris, 1953. Esta Editorial parece ser una de las principales promotoras en Francia del pensamiento neoliberal, ya desde la década de 1930 . 
organizador del mismo, con el objeto de dejar atrás el liberalismo manchesteriano de carácter naturalista y hasta cierto punto culpable de la crisis política europea que en 1938 mostraba ya los síntomas de un conflicto a gran escala. Esta alusión a Rougier como acuñador de la expresión no es del todo exacta, ya lo veremos más adelante, incluso en el coloquio ${ }^{20}$. Bernard Walpen discutirá lo anterior, y plantea que el término Neoliberalismus ya había sido usado en 1925 por Hans Honegger, para describir una corriente existente al menos en Suiza ${ }^{21}$.

Foucault va a recordar en $1979^{22}$ el dato aportado por Baudin, durante el curso Naissance de la biopolitique, y dedicará algunos análisis al coloquio, antes de pasar al análisis del ordoliberalismo. Este curso de Foucault no lo conoceremos hasta el 2004, año en que va a ser publicado por primera vez. No obstante, es importante lo que plan-

20 Los diálogos del congreso muestran que la expresión es propuesta por Marlio, aunque Baudin e incluso Denord se la adjudiquen a Rougier. No es el único malentendido; pues Escalante le adjudica el nombre a Rüstow: "Se discutió igualmente en 1938 el nombre que podría adoptar el movimiento. Rueff propuso "liberalismo de izquierda", Boudin [SIC!] sugirió "individualismo", Rougier prefería "liberalismo positivo" finalmente a propuesta de Rüstow, se optó por "neoliberalismo", para dejar claro que no se trataba del liberalismo clásico manchesteriano, pero tampoco del nuevo liberalismo de Hobhouse y Hill Green" Ver Escalante Gonzalbo, Fernando. Historia mínima del neoliberalismo. Colegio de México, México D.F., 2015. Al menos en las actas tal como las ha reeditado Audier, no hay registro de una intervención de Rüstow sobre esta materia, aunque es posible que las actas tengan algunas omisiones, en primer lugar por la intervención muy temprana de Rueff sobre este tema, quien se opone a la expresión "neo" en las discusiones que siguieron a la alocución inicial de Lippmann. Ver Centre international d'études pour la rénovation du libéralisme. «Le Colloque Walter Lippmann». En Audier, Serge. Le colloque Lippmann. Aux origines de "neo-libéralisme". Le bord l'eau, Paris, 2012, p. 430. Una lectura atenta de las páginas anteriores mostrará que al menos en el texto de las actas no se consigna mención al tema. Por lo cual, o la intervención de Rueff quedó por alguna razón fuera de contexto o alude a alguna afirmación anterior que ha sido omitida. Por otra parte, el prefacio escrito por Rougier aclara que las intervenciones de Hayek realizadas en inglés, no se mecanografiaron en directo, y las trasncripciones de las actas recogen sólo lo que se pudo reconstituir posteriormente de ellas. Ver Centre international d'études pour la rénovation du libéralisme. «Le Colloque Walter Lippmann». En Audier, Serge. Le colloque Lippmann. Aux origines de "neo-libéralisme". Le bord l'eau, Paris, 2012, p. 409, nota 2.

21 Walpen, Bernhard. «Auf dem Pilgerberg oder: Dialektik der Freiheit. Eine kurze Geschichte des Neoliberalismus», p. 210.

22 Clase del 14 de febrero. Foucault, Michel. Naissance de la biopolitique, p. 138 ss. 
tea Foucault en este curso, porque muestra una diferenciación clara entre lo que será posteriormente la escuela austro-norteamericana y el neoliberalismo alemán u ordoliberalismo, e incluso las posibilidades de un socioliberalismo. Aunque -es necesario reconocerlo- el análisis de Foucault sobre esto tiene algunos saltos documentales en cuanto al tratamiento con las fuentes, algunas confusiones y un tratamiento del problema demasiado en bloque. Por supuesto, esto podemos decirlo con más soltura a 36 años del curso, sin embargo en 1979 los aportes de Foucault resultan visionarios respecto a la importancia que el neoliberalismo alcanzará en la década siguiente ${ }^{23}$.

El coloquio de 1938 me parece importante, entonces, y le dedicaré algunos análisis, en primer lugar porque ayuda a romper la hegemonía de las propuestas neoclásicas y austro-norteamericanas, mostrando al mismo tiempo que las medidas de estas escuelas y que han resultado a la larga una de las posiciones políticas más influyentes para la América Latina de los últimos 40 años, son no sólo posturas económicas o económico-técnicas; sino que en buena medida e incluso principalmente, se trataría de posturas de economía política o filosóficas. Además, se muestra cómo el nacimiento de este Neoliberalismo está envuelto en una serie de fracturas, de modo que el coloquio evidencia de inmediato tanto la adhesión a un programa común de renovación del liberalismo, como las posiciones que en el siglo XX separarán aguas entre al menos dos formas de entender tal propuesta de renovación. Un estudio de François Denord nos ayuda también a ver la importancia de este coloquio, pues revela que no se trata de un evento aislado ${ }^{24}$. Denord recuerda que la Librairie de Médicis, casa editorial que publica el Coloquio, publicará también otros volúmenes

23 Una valoración actual del papel de este curso frente al tema del neoliberalismo y un desarrollo interesante de ciertros debates asociados puede encontrarse en López, Pablo. «Sigue cierta algarabía. Foucault, el neoliberalismo y nosotros». En Castro, Rodrigo; Salinas Adán. La actualidad de Michel Foucault. Escolar y mayo, Madrid, 2016, pp. 231-254.

24 Ver Denord, François. «Aux origines du néo-libéralisme en France. Louis Rougier et le Colloque Walter Lippmann de 1938». La Découverte | Le Mouvement Social. $N^{\circ} 195,2001-2$, pp. 9-34. 
en esta línea antes de la fundación de la Sociedad de Mont Pèlerin, de modo que el coloquio sería parte de un proceso en curso ${ }^{25}$. Plehwe concuerda con lo anterior y se encarga de mostrar que "quince de entre los que fueron invitados, llegarán posteriormente a participar en la fundación de la Société du Mont Pèlerin, nueve años después"26. En la misma línea, Walpen recordará que como consecuencia del coloquio se formó un centro de estudios, y se fundó una revista especializada, además del evidente programa de acción que el coloquio pretende ${ }^{27}$. De modo que aunque haya antecedentes teóricos claros antes del coloquio, hay que tener a la vista el influjo y el valor político de esta reunión a la que asistirán algunas de las figuras políticas más relevantes de la reconstrucción alemana, por una parte, y por otra, algunos de los futuros promotores de la escuela de Chicago. Éstos son algunos aspectos que dan cuenta de la relevancia del evento, sus discusiones, y me parece que justifican detenerse en un coloquio bastante olvidado y muy poco difundido ${ }^{28}$ realizado en 1938 en París y del que aparentemente no salió nada muy claro o conocido. Por otra parte, la reedición de las actas del coloquio a cargo de Serge Audier, después de 73 años ${ }^{29}$ ha hecho posible que podamos ponernos en contacto

25 Denord reconstruye el orden de las publicaciones más importantes en está línea, desde el archivo de la fundadora de la editorial. Ver Denord, François. «Aux origines du néo-libéralisme en France. Louis Rougier et le Colloque Walter Lippmann de 1938», pp. 18ss.

26 Ver Plehwe, Dieter. «Introduction». En Mirowski, Philip; Plehwe, Dieter. The Road From Mont Pèlerin. Harvard University Press, Cambridge-London, 2009, p. 13.

27 Walpen, Bernhard. «Auf dem Pilgerberg oder: Dialektik der Freiheit. Eine kurze Geschichte des Neoliberalismus», p. 212.

28 De hecho Ghersi llega a afirmar que no hubo actas ni publicaciones del congreso: «Participaron en el seminario gente de la talla de Rueff, Hayek, Von Mises, Rustow, Röpcke, Detœuf, Condliffe, Polanyi, Lippman y el propio Baudin, entre otros. Como no se tuvo actas ni publicaciones del coloquio, el único testimonio de primera fuente que ha quedado es el citado libro de Baudin, escrito hacia mediados de la década de 1950». Ghersi, Enrique. «El mito del neoliberalismo», p. 293.

29 Ver Audier, Serge. Le colloque Lippmann. Aux origines de "neo-libéralisme". Le bord l'eau, Paris, 2012. Incluye un extenso, quizás exagerado estudio introductorio de casi 400 páginas, y posteriormente reedita las mucho más breves actas del congreso publicadas orginalmente en 1939. Ver Centre international d'études pour la rénovation du libéralisme. «Le Colloque Walter Lippmann». Librairie de Médicis, Paris, 1939. 
con estas discusiones y que ahora pueda apuntar algunas cosas que podrían tener cierta relevancia.

Contexto $^{30}$. En 1937 Walter Lippmann, un reconocido periodista e intelectual público norteamericano de origen judío, había publicado The Good Society ${ }^{31}$, un libro que se interrogaba entre otras cosas por el problema de la Libertad en el nuevo contexto político de surgimiento del fascismo, el nazismo y el bolchevismo, es decir, ante el surgimiento de regímenes autoritarios, y por otra parte las insuficiencias del liberalismo clásico a nivel político y económico. Un viaje de Lippmann a Francia permite que Louis Rougier, un filósofo francés que después tendrá alguna importancia en la diplomacia francesa, convoque este coloquio en Paris, y en el que se darán cita algunos intelectuales alemanes, franceses y austriacos, principalmente. El objetivo del coloquio es por una parte conmemorativo o de homenaje al libro de Lippmann, y por otra parte programático, al menos en las expectativas de Rougier, que propondrá como objetivos un diagnóstico de la crisis del liberalismo y las posibilidades de su renovación como elementos principales para el coloquio. El evento se desarrolla entre el 26 y el 30 de agosto de 1938. Y se organizará en siete mesas temáticas. Entre los algo más de 25 asistentes, podemos contar a Raymond Aron (Francia), R. Auboin (Francia), Louis Baudin (Francia), M. Bourgeois (Francia), J. Castillejo (España), J. B Condliffe (Gran Bretaña) A. Detœuf (Francia), Von Hayek (Gran Bretaña), Heilperin (Polonia), B. Hooper (Estados Unidos), B. Lavergne (Francia), W. Lippmann (Estados Unidos), E. Mantoux (Francia), R. Marjolin (Francia), L. Marlio (Francia), Mercier (Francia), Von Mises (Escuela austriaca), A. Piatler (Francia), M. Polanyi

30 Una explicación del contexto, todavía breve pero más amplia y completa que el esbozo que aquí propongo puede ser revisada en Alvarez-Uría. Fernando. «Karl Polanyi y sus contemporáneos. Sobre la subordinación de los mercados a los valores de la civilización y de la libertad». ENCRUCIJADAS. Revista Crítica de Ciencias Sociales, N7, 2014, pp. 16-35.

31 Lippmann, Walter. The Good Society. Little, Brown \& Co. Boston, 1937. Las traducciones del libro son bastante llamativas por las modificaciones en el titulo. En francés ver Lippmann, Walter. La cité libre. Librairie de Médicis, Paris, 1938. En castellano la traducción de Luis Montes de Oca: Ver Lippmann, Walter. Retorno a la libertad, Unión Tipográfica Hispanoamericana, México, 1940. 
(Gran Bretaña), St. Possony (Austria), W. Röpcke (Escuela austriaca), Louis Rougier (Francia), Jacques Rueff (Francia), M. Rustow (Turquía), Dr. Schutz (Austria), Marcel van Zeeland (Bélgica).

\section{Discusiones sobre la expresión "neoliberalismo" en el coloquio de 1938}

Entonces luego de esta introducción y de algunos rodeos necesarios, quisiera entrar directamente en el texto del coloquio, para señalar algunos puntos que me parecen importantes. Por supuesto no son los únicos aspectos importantes, y mi selección obedece a los aspectos que se relacionan más directamente con mi investigación. Así que ustedes pueden escoger otros aspectos también; esto no es una síntesis, sino más bien una invitación a conocer el coloquio. El primer tema del coloquio que quiero tocar se concentra especialmente en la sexta sesión, y se relaciona con el nombre que estos autores proponen para su movimiento.

Ya adelantaba en la introducción que Baudin asignó a Rougier el uso original del término 'neoliberalismo'. Este tema del nombre no deja de ser sintomático respecto a los acuerdos y escisiones. Al menos en las actas publicadas del Coloquio no es Rougier, sino Louis Marlio quien propone esta denominación, en la sexta sesión del coloquio. Aunque su propuesta es un poco casual. Rueff acaba de comentar que las propuestas de Lippmann para una agenda liberal, le parecen las más correctas y que calificaría esto como un liberalismo de izquierda. Asunto sin duda sensible: "porque tiende a dar a las clases más pobres, el mayor bienestar posible" y a continuación añade: "Por esto me sumo sin reservas a las propuestas del Sr. Lipmann". Marlio responde:

"Estoy de acuerdo con el Sr. Rueff, pero no quisiera que se empleara la expresión "liberalismo de izquierda" porque no me parece justa y hay, actualmente, más o menos la misma visión a la izquierda que a la derecha. Entonces, da la impresión de que estamos defendiendo la causa de un partido político. Considero mejor que se llame a 
esta doctrina "liberalismo positivo", "liberalismo social" o "neoliberalismo", pero no la expresión [la palabra] 'de izquierda' que indica una posición política. El color político no debe interferir" ${ }^{\prime \prime 2}$.

Luego Rougier, al realizar el prólogo de la edición -prólogo en todo caso posterior al coloquio mismo-, recoge esta expresión. Hablando sobre el libro de Lippmann que motivó el congreso afirma ya en el primer párrafo del prólogo:

"Esta armonía no establecida, ese concierto no concertado, esbozó las líneas generales de una doctrina llamada por algunos «liberalismo constructor» designada por otros «neocapitalismo» y aquel uso que parece prevalecer le da [de dar] el nombre de «neoliberalismo»" ${ }^{\prime 3}$.

Estas palabras hacen pensar, en todo caso, que se trata de un término en uso, como piensa Walpen, mucho más que una expresión acuñada en el coloquio como afirma Baudin. Pero de todos modos se trata de una propuesta de renovación y transformación del liberalismo. Baudin añadirá alguna línea interesante a la discusión durante la primera sesión del congreso: "La antítesis fundamental consiste en la oposición entre el individualismo y el socialismo, como lo exigen las palabras mismas. El liberalismo que, llevado al extremo, se convierte en el anarquismo, por el contrario el intervencionismo que, siendo exagerado, conduce al estatismo. La palabra individualismo nos parece preferible a la palabra liberalismo" ${ }^{\prime 34}$. $Y$ además añade:

"Último argumento: nosotros podemos aclarar el significado que damos a liberalismo, esta palabra mantendrá aquello que continúa siendo. Nosotros seremos, guste o no,

32 Todo el diálogo puede consultarse en Centre international d'études pour la rénovation du libéralisme. «Le Colloque Walter Lippmann», p. 487.

33 Centre international d'études pour la rénovation du libéralisme. «Le Colloque Walter Lippmann», p. 409.

34 Centre international d'études pour la rénovation du libéralisme. «Le Colloque Walter Lippmann», p. 428. 
calificados de manchesterianos y vistos como discípulos de Bastiat, o incluso de Yves Guyot o Molinari. El liberalismo, para muchos, es el laissez-faire, el laissez-passer [dejar-pasar] y se añade el laissez-souffrir [dejar-sufrir]. Sin querer ser oportunista, creemos que esta palabra gastada es peligrosa. Nosotros preferimos tomar el individualismo por bandera, puestos a la sombra de los grandes clásicos: Adam Smith, J-B Say y Stuart Mill"35.

Me parece que estas discusiones que he traído a colación a propósito del nombre expresan una escisión interesante. El coloquio se convoca con la pretensión de proponer un proceso de renovación del liberalismo, al menos en principio, y el abanico de posiciones es amplio. Desde quienes se sentirían cómodos incluso frente a una imagen como la de un liberalismo de izquierda, hasta quienes proponen completamente cambiar de léxico, en favor de una propuesta menos implicada con el manchesterianismo. Baudin, en la intervención anterior -y es algo que también realiza Rougier y Lippmann en las intervenciones iniciales del congreso-, apela a la tradición del liberalismo político, frente al problema de la intervención. Mantoux llegará a ser implacable respecto a la noción misma de liberalismo:

"Es increíble que una filosofía política tan amplia, y que no hace sino interpretar el avance de la libertad humana a través de las edades, ahora se asocia en la mente del público, por un accidente histórico, a la doctrina de una pequeña secta de los economistas del siglo XIX. Por lo tanto, porque condenamos las ideas de Dunoyer y Spencer, se cree que se condena la misma libertad" y agrega... "El significado de la palabra libertad es obviamente universal. Mientras permanece asociada con una determinada concepción de la política económica, cualquier discusión sobre el liberalismo será imposible" ${ }^{\prime 36}$.

35 Centre international d'études pour la rénovation du libéralisme. «Le Colloque Walter Lippmann», p. 428.

36 Centre international d'etudes pour la renovation du liberalisme. «Le Colloque Walter Lippmann», p. 430. 
Detœuf agrega:

"Para mí, la palabra liberalismo se ha convertido en equivalente de manchesterianismo. Pero nosotros no somos todos manchesterianos. La idea de la justicia coexiste para algunos de nosotros con la idea de libertad y nos diferencia de los liberales manchesterianos" ${ }^{\prime 37}$.

Entonces esta polémica sobre el nombre muestra una espina teórica y política que molesta al menos a un grupo importante de los asistentes. Para un sector de los asistentes, renovar el liberalismo quiere decir, proponer un proyecto diferente al manchesterianismo y a la aplicación dogmática del laissez faire. Mientras que para otros resulta completamente necesario afirmar cierta continuidad, 'hablar claro' decir directamente 'liberalismo': "Yo soy hostil [me opongo] a la palabra "neo" que se ha propuesto. Si es nuestra convicción que nuestro esfuerzo debe tender a restaurar el liberalismo, como base permanente de los regímenes económicos y sociales, hay que decirlo a plena luz [abiertamente], en la forma más provocativa. El único problema [en el mundo] es saber si vamos hacia el liberalismo o no, y debe demostrarse claramente" ${ }^{\prime 3}$. Pienso que esta disputa anterior puede leerse de dos maneras; primero como la separación del liberalismo político del manchesterianismo económico, o incluso como la negación activa de reducir toda posible economía liberal a la simplificación del laissez faire; la segunda manera de interpretarlo es como una operación retórica. Pienso que no se puede desechar ninguna de estas dos lecturas, pues son muy claras a lo largo del

37 Centre international d'etudes pour la renovation du liberalisme. «Le Colloque Walter Lippmann», p. 431.

38 Esto resulta contradictorio con la propuesta del propio Rueff de hablar de liberalismo de izquierda, pienso que se trata de una forma de acomodarse a la discusión, a menos que me haya equivocado completamente en la traducción de este pasaje "Je suis hostile au mot «néo» qu'on a proposé. Si c'est notre conviction que notre effort doit tendre à restaurer le libéralisme, comme base permanente des régimes économiques et sociaux, il faut le dire en pleine lumière, sous la forme la plus provocante. Le seul problème dans le monde est de savoir si on va vers le libéralisme ou non, et il faut le montrer clairement". Centre international d'etudes pour la renovation du liberalisme. "Le Colloque Walter Lippmann», p. 430. 
coloquio, la intención de proponer estrategias económicas diferentes a las del manchesterianismo; pero al mismo tiempo, los excesos retóricos de ciertos pasajes nos hablan de una clara estrategia de recubrimiento ideológico. Entonces este problema del nombre, nos muestra varias cosas importantes. Primero que hay un abanico de posiciones en las que aparece como mínimo común o aglutinador inicial el proyecto de renovar el liberalismo. Sin embargo, se ve con claridad que 'renovar el liberalismo' no significa la misma cosa para los diferentes interlocutores. No hay ese aglutinamiento ideológico tan robusto, típico de los neoliberales actuales que manejan un cuerpo doctrinario común. Tampoco hay una figura clara de 'padre fundador' del movimiento como a veces se pretende con Hayek e incluso con Friedman en la literatura más divulgativa; aquí Von Mises juega un papel importante, pero hay otras figuras fuertes, la de Lippmann, por supuesto, y la de Rueff que se destaca en momentos claves del coloquio, y por supuesto la figura de Marlio. Por otra parte, la crítica del manchesterianismo es muy decidida y las defensas muy tímidas, de hecho ninguna defensa declarada, esto es importante si lo comparamos con la hegemonía neoclásica del neoliberalismo actual, que no está en el coloquio. Pasemos a un segundo punto entre los temas del coloquio.

\section{La explicación de los monopolios}

Este segundo tema en el que me quiero detener se refiere ya a una cuestión doctrinaria, sobre la formación de monopolios y la explicación de la declinación del liberalismo. Se trata de un tema discutido sobre todo en la primera sesión del coloquio

Adelanto que sobre esto vencerán relativamente los autores más cercanos a la ortodoxia clásica, representada especialmente por Von Mises en este tema. Una pregunta de Rougier abre la primera sesión del congreso. " ¿El declinar del liberalismo es inevitable por su tendencia a la concentración de las empresas, de los capitales... la concentración económica es un efecto necesario de la evolución económica o el 
resultado de privilegios jurídicos?" ${ }^{\prime 39}$. Hasta cierto punto puede verse la inspiración del marxismo cientificista en la pregunta, es decir que el declinar del capitalismo se debe a causas endógenas e inevitables. Por otra parte también está de fondo el constructivismo jurídico de Lippmann, quien ha planteado en su texto, que no es posible pensar un sistema competitivo sin el entramado jurídico y social necesario, y que es por supuesto una cuestión "artificial", no natural, y socialmente construida y modificable. Volviendo a la pregunta, no pienso que Rougier tenga una premisa marxista de trabajo, pienso que recoge esta pregunta pues se trata de una pregunta o más bien de una objeción importante del marxismo de la época. Si la explicación marxista resulta adecuada, no tiene sentido hablar de una renovación del liberalismo, con lo que el coloquio queda sin posibilidad de seguir avanzando. Por supuesto que parece una concesión innecesaria, excesivamente teórica y poco práctica. Pero es un punto de partida lógico y al mismo tiempo un agasajo para la exposición de Von Mi$\mathrm{ses}^{40}$. Veremos que sus explicaciones al respecto son previsiblemente protagónicas. Propone diferenciar entre concentración y monopolio ${ }^{41}$. La concentración, sea o no sea una tendencia natural de la economía, según Von Mises, tiene aspectos ventajosos como el aumento del capital fijo, lo que implica la posibilidad de inversión tecnológica e incluso redunda en la baja de precios. De este modo, la característica indeseable de los monopolios no es la concentración; ni tampoco la posición monopólica de la oferta y la venta ${ }^{42}$; los monopolios tienen

39 Centre international d'etudes pour la renovation du liberalisme. «Le Colloque Walter Lippmann», p. 433.

40 Es necesario recordar que en Die Gemeinwirtschaft, poco más quince años antes del coloquio, Von Mises había hecho un examen suficiente de algunas de estas objeciones. Para el tema de la concentración en la teoría marxista y los monopolios como anteceedentes del socialismo ver Mises, Ludwig von. Die Gemeinwirtschaft, p. 352ss. Para la propuesta de Mises que explica la concentración en las empresas, ver p. 361 ss. Sobre los monopolios y su contribución, ver pp. 375-383.

41 Es una finta interesante; pues -al menos hasta donde alcanzo a ver- la explicación marxista más extendida en la época era la de Imperialismo como fase superior del capitalismo, donde la concentración monopólica es precisamente una de las características más decidoras de la evolución del capitalismo global.

42 "Un gran número de productores tiene la exclusividad del mercado en el sentido de que sólo ellos pueden proporcionar un producto de una calidad determinada. Pero 
como marca distintiva la fijación de precios y la principal explicación de la formación de monopolios no es una supuesta tendencia natural del capitalismo a la concentración ${ }^{43}$, sino la intervención estatal que genera distorsiones en el mercado. "C'est la législation, c'est la politique, qui ont créé la tendance au monopole"44. Marlio incluso apoya los beneficios de la concentración de capital en las grandes empresas por sobre sus inconvenientes innegables ${ }^{45}$.

Hasta aquí habría un éxito relativo de la postura de Von Mises, que incluso agrega a sus antiguas explicaciones de la teoría marxista, esta nueva diferenciación entre Concentración y Monopolio. Pero la discusión no está del todo cerrada, hay que recordar el segundo elemento que articula la alocución inicial de Rougier. Me refiero al construccionismo jurídico que Lippmann ha incorporado en su libro The good Society. Para Lippmann, una economía de la libre competencia en el mundo moderno, requiere una jurídica que la norme, le entregue legitimidad, etc. De hecho, requiere de una serie de condiciones jurídicas que la hagan existir: sociedades anónimas, monedas y otros instrumentos

la mayoría de ellos no podría aumentar los precios sin una disminución significativa de sus ganancias como consecuencia de una disminución en sus ventas. Estos productores tienen el monopolio de la producción y venta, pero no están en condiciones para obtener precios de monopolio". Centre international d'etudes pour la renovation du liberalisme. «Le Colloque Walter Lippmann», p. 438.

43 Mises reitera el error que en su opinión implica afirmar la tesis marxista de la tendencia a la concentración: "[...]en la doctrina marxista, la concentración resulta del libre juego de las fuerzas económicas. Mientras que el desarrollo de los monopolios de hecho ha sido liderado por una política económica intervencionista". Centre international d'etudes pour la renovation du liberalisme. «Le Colloque Walter Lippmann», p. 434. Ejemplica en las líneas siguientes con la estatización de las empresas de ferrocarriles, para mostrar el monopolio ferroviario creado por la intervención del Estado: "dans la doctrine marxiste, la concentration résulte du libre jeu des forces économiques, alors que le développement des monopoles a été en fait amené par une politique économique interventionniste".

${ }_{44}$ Centre international d'etudes pour la renovation du liberalisme. «Le Colloque Walter Lippmann», p. 435.

45 "La concentración de las empresas es algo útil y propicio para el desarrollo de la economía y su progreso. Es útil. No me asombro por las objeciones del Señor Lippmann. No niego que la concentración industrial tiene inconvenientes, pero son inferiores a sus beneficios". Centre international d'etudes pour la renovation du liberalisme. «Le Colloque Walter Lippmann», p. 436. 
valorables, etc. Por supuesto, nada de esto puede ser considerado un elemento natural de la economía, sino condiciones construidas socialmente; pero al mismo tiempo, necesarias para el libre juego de la competencia. Este construccionismo es parte del telón de fondo del coloquio. Rougier lo pone de manifiesto en la alocución inicial:

El segundo mérito del libro de Walter Lippmann es haber demostrado que el régimen Liberal no es sólo el resultado de un orden natural espontáneo como lo declaraban, en el siglo XVIII, numerosos autores sobre la Ley Natural, sino que es también el resultado de un orden legal que supone un intervencionismo jurídico del Estado. La vida económica se desarrolla en un marco legal, que establece el régimen de la propiedad, de los contratos, de las patentes, de la quiebra, la situación de las asociaciones profesionales y las sociedades comerciales, la moneda y la banca, todas estas cosas no son datos de la naturaleza, como las leyes del equilibrio económico, sino creaciones contingentes del legislador ${ }^{46}$.

Quisiera hacer un comentario fuera del coloquio. Esto que estamos comentando parece novedoso, ya que nos hemos acostumbrado a pensar que el planteamiento neoliberal sea naturalista, que crea en la naturalidad del mercado y en la esencialidad de sus leyes y en la no intervención. No es tan novedoso, Foucault en 1979 ya se había dado cuenta de que el neoliberalismo pone en cuestión el naturalismo clá$\mathrm{sico}^{47}$, pero se trata de una característica más propia del pensamiento ordoliberal. Volvamos ahora al coloquio. Von Mises y Hayek ${ }^{48}$ guarda-

46 Centre international d'etudes pour la renovation du liberalisme. «Le Colloque Walter Lippmann», p. 414-415.

47 Comenta especialmente los trabajos del ordoliberalismo alemán y la idea de "mar-

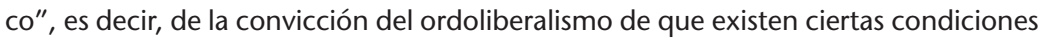
que se deben crear y mantener para que un mercado funcione. Ver Foucault, Michel. Naissance de la biopolitique. Pp. 107-125, 207, 249, 329-330.

48 En Human action, en 1949, Von Mises propondrá la noción de cataláctica como sustituto para la noción de economía. Pues la palabra eocnomía implica en sí misma una organziación o adminitración intencionada. Ver Mises, Ludwig von. Human action. A Treatise on Economics. Ludwig von Mises Institute, Alabama, 1998, pp. 233-257. Hayek ampliará el uso de este vocablo y utilizará la noción de catalaxia 
rán un silencio relativo sobre este aspecto del libro de Lippmann. Digo 'relativo', pues aunque no se refieren a este punto en concreto, Von Mises va a apoyar las tesis naturalistas o de organización espontánea como se ha visto sobre los monopolios, y se verá también respecto al problema del desempleo. Hay aquí una especie de discusión latente que Von Mises no llega a entablar en el coloquio. Es cierto que Rougier, Lippmann e incluso Rüstow insistirán en el fracaso práctico del laissez faire $^{49}$, y por tanto de la inviabilidad de la explicación que apuesta por la espontaneidad u organización natural. Rougier es severo en la materia desde la alocución inicial.

\begin{abstract}
"No es suficiente decir que el problema del desempleo no se plantearía si las migraciones de mano de obra fuesen libres, ya que hoy en día es un hecho que no lo son. No es suficiente decir que a la larga una crisis económica, por grave que sea, se reabsorbe de forma automática, sin la intervención del Estado, por la tendencia espontánea al restablecimiento del equilibrio, si las masas sufren y no tienen la paciencia de esperar el largo periodo de recuperación de los ciclos de gran amplitud. No podemos, por otra parte, regresar desde una economía dirigida a una economía progresivamente liberal que por un intervencionismo en sentido contrario,
\end{abstract}

\footnotetext{
para explicar que habría una organización espontánea del mercado, no natural en el sentido clásico, pero tampoco construida artificialmente o dependiente de un marco que haya que mantener por medios construidos activamente. Ver Hayek, Friedrich. «The Principles Of A Liberal Social Order» En Hayek, Friedrich. Studies In Philosophy, Politics And Economics. Rotledge, London, 1967, p. 161ss. Una década más tarde en 1978 confirmará y profundizará en el uso de esta noción. Ver Hayek, Friedrich. «The Atavism of SociaL Justice». En Hayek, Friedrich. New studies in philosophy, politics, economics and the history of ideas. Routledge, London, 1996, p. 60.

49 También habría un fracaso teórico de las tesis 'antropológicas' por ejemplo sobre la elección racional: "[...]Uno puede reconocer un tercer mérito al libro de Walter Lippmann: el de reintegrar los problemas económicos en su contexto político, sociológico y psicológico, en virtud de la interdependencia de todos los aspectos de la vida social. ... A partir del homo œconomicus, que actúa de una manera puramente racional a sus mejores intereses, ella debe encontrar al hombre de carne, de pasión y de inteligencia limitada que se somete a entrenamientos gregarios, obedece a creencias místicas y nunca sabe calcular las incidencias de sus actos". Centre international d'etudes pour la renovation du liberalisme. «Le Colloque Walter Lippmann», p. 416.
} 
tenga por propósito reestablecer un equilibrio no forzado. En resumen, no hay que contentarse más con razonar en abstracto; debemos aceptar el mundo tal como es y estudiar cómo, a pesar de su sandez, podemos tratar de mejorarlo" ${ }^{50}$.

Como decía, pienso que a pesar de ciertas provocaciones, Von Mises y Hayek guardan silencio sin defender el laissez faire, aunque reactivando la explicación de que todo mal económico, toda consecuencia desastrosa es producto de la intervención. Como veremos un poco más adelante a propósito del empleo, la pauperización y el seguro de desempleo.

Pienso que en esta discusión silenciada, Detœuf desliza una propuesta del mayor interés, vuelvo al problema de los monopolios: Frente a la concentración y el monopolio, no sólo es posible una acción del Estado que favorezca el monopolio y consecuentemente vaya en contra del natural desarrollo de la economía -como diagnosticaba Von Mises-; sino que además el Estado podría, eventualmente, actuar de modo favorable al desarrollo natural, o al menos, la acción del Estado no debe ser considerada siempre un intervencionismo artificial. Para esto, Detœuf retoma el ejemplo principal de Von Mises sobre la nacionalización de las empresas ferroviarias. Según Von Mises esto era precisamente un ejemplo de intervencionismo que había creado un monopolio ferroviario. El análisis de Detœuf es interesante:

"Los ferrocarriles constituyen hoy en día, para todos los Estados, una carga verdaderamente grande. Allí donde pertenecían a empresas privadas, el Estado ha sido llevado a sostenerlos, para evitar la ruina de una sección entera de la población. Ahora la pregunta es si un Estado moderno puede soportar que gran parte de la población esté arruinada. Si es así, el intervencionismo es de origen político; Si no, él es de origen natural; es una reacción espontánea de defensa del organismo social. El problema que se pre-

50 Centre international d'etudes pour la renovation du liberalisme. «Le Colloque Walter Lippmann», p. 416. 
senta para el liberalismo manchesteriano viene de que su evolución ha conducido a una situación en la que todo el mundo se encuentra más o menos arruinado o sin trabajo. La comunidad ha tratado de remediar este estado de cosas, no en virtud de teorías marxistas o colectivistas. Ella sólo ha intentado hacer lo mejor y ha encontrado, después, las justificaciones a las intervenciones que no pudo evitar"51.

Rüstow polemiza con Detœuf pero también profundiza uno de sus argumentos, hablando incluso de las funciones policiales del Estado frente a los mercados degenerados, es decir que distorsionan la libre competencia en favor de intereses particulares y relaciones de colusión $^{52}$. Hay aquí un silencio; pero también un desplazamiento. Ante el silencio de Von Mises, Detœuf desliza los rudimentos de una política neoliberal. Se comienza a proponer las bases de un Estado como herramienta de mercado. El problema entonces será decantar una norma de acción para la intervención del Estado. Esto lo retomaré un poco más adelante.

\section{Sobre el desempleo y la intervención del Estado}

Las discusiones anteriores se retomarán en la cuarta sesión del coloquio sobre El Liberalismo y la cuestión social, que -como he comentado- termina por referirse casi exclusivamente al desempleo, aunque

51 Centre international d'etudes pour la renovation du liberalisme. «Le Colloque Walter Lippmann», p. 435.

52 "Obviamente, la tendencia a sobrepasar el óptimo económico de la concentración no puede ser una tendencia de orden económico, en el sentido del sistema competitivo. Es más bien una tendencia monopólica, neo-feudal, depredadora, que no puede tener éxito sin el apoyo del Estado, de las leyes, de los tribunales, de los magistrados, de la opinión pública [...]

Por lo tanto, no es la competencia que mata a la competencia. Es más bien la debilidad intelectual y moral del Estado, que aborda ignorante y negligentemente sus deberes de custodiar el mercado, permite degenerar [laisse dégénérer] la competencia, después [laisse abuser] deja abusar de sus derechos por elegantes saqueadores [chevaliers pillards] para dar el golpe de gracia a esta competencia degenerada". Centre international d'etudes pour la renovation du liberalisme. «Le Colloque Walter Lippmann», p. 438. 
desde la alocución inicial de Rougier está presente el problema de 'la cuestión social ${ }^{\prime 53}$. Nuevamente las posiciones son claras: Rueff, Mises y Condliffe defienden que el desempleo sostenido es causado por el intervencionismo. Es decir, insisten en la ortodoxia clásica. Ahora bien, el problema del pauperismo es vuelto a poner por Lippmann. Quisiera reproducir uno de los diálogos de esta sesión especialmente entre Rueff y Lippmann. Luego que el primero ha argumentado que el desequilibrio económico como criterio general es la principal explicación del desempleo, termina su intervención con las siguientes afirmaciones:

"El sistema liberal tiende a garantizar a las clases más necesitadas, el máximo de bienestar.

Todas las intervenciones del Estado tienden económicamente a empobrecer a los trabajadores. Todas las intervenciones del Gobierno aparentan mejorar la condición de la mayor cantidad, pero no hay ninguna otra manera de hacerlo que aumentar la masa de los productos para compartir" ${ }^{24}$.

53 "La segunda cuestión previa es la siguiente: ¿El liberalismo económico puede satisfacer las demandas sociales de las masas? Estas exigencias han existido siempre; pero, debido al prodigioso auge de la población europea y americana en el siglo XIX, a raíz de la difusión de la educación, como resultado de las nuevas solidaridades profesionales [asistencia social organizada], de repente recibieron una conciencia clara y convincente de sí mismas. Las masas reclaman indeclinablemente [sin remisión] un mínimo de seguridad vital: esto es plantear el tema de la crisis y el problema del desempleo. Es cierto que el desempleo crónico es en la mayor parte el resultado del seguro de desempleo. ¿Hay que contentarse con esta constatación y no buscar cómo remediarlo de otro modo que [no sea] por la supresión de este seguro, recurriendo a la reducación profesional por ejemplo, si se demuestra que las masas nunca retrocederán del principio de la seguridad social? En una palabra, ¿puede el liberalismo responder a las exigencias sociales del mundo actual? Porque, lo que atrae a las masas a los Estados totalitarios, no hay ninguna duda, es la creencia errónea de que la economía planificada puede garantizarles un mínimo vital, da lo mismo si ese mínimo es un plato, un cuartel y un uniforme. Las masas están dispuestas a abandonar a su libertad en las manos de alguien, líder o mesías, que les promete seguridad". Centre international d'etudes pour la renovation du liberalisme. «Le Colloque Walter Lippmann», p. 417.

54 Centre international d'etudes pour la renovation du liberalisme. «Le Colloque Walter Lippmann», p. 461. 
Lippmann replica " ¿Es posible aliviar el sufrimiento en la movilidad de un sistema de mercado privado? Si la balanza debe dejarse siempre a sí misma, esto implica un gran sufrimiento. ¿Podemos remediar tanto sufrimiento por medidas como la imposición de un impuesto especial sobre los negocios prósperos?" A lo que Rueff responde "Hay que hacer lo máximo por los trabajadores, pero todo debe ser como parte de un presupuesto equilibrado". Y añade "El sistema de seguros de desempleo inglés tiene grandes lagunas, pero desde el momento en que el presupuesto inglés es equilibrado, el sistema puede durar indefinidamente. La fijación a priori de salarios, independientemente del número de desempleados, condujo al desastre" ${ }^{\prime 55}$.

Un poco más adelante, luego de algunas intervenciones, el problema parece decantar, el propio Rueff lanzará una pregunta programática que encierra el desplazamiento general que intento mostrar: "El verdadero problema es cuál es el límite de la intervención en el Estado liberal. ¿Cuáles son las modalidades de intervención coherentes con el mecanismo del precio?"56. Creo que aquí hemos llegado a un punto clave que merece algunos comentarios y que se viene anunciando desde lo que comentaba en la parte anterior. Me gustaría explicitar lo que veo en estos diálogos. Se trata de un desplazamiento claro, pero también específico respecto al manchesterianismo entendido como laissez-faire sin intervención. Lo primero, como veíamos antes, es la aceptación tácita de una política neoliberal. El Estado juega un papel, por lo menos como custodio del sistema competitivo; pero aquí hemos encontrado una fórmula que muestra cuál es la medida de esa política: Una fórmula de intervención del Estado liberal. Esta fórmula, esta clave de discernimiento de la correcta acción, consiste en que toda acción del Estado debe ser coherente con el sistema de libre fijación de precios. Es interesante que la serie de escisiones que hemos atestiguado lleven finalmente a encontrar esta moneda común en el

55 Todo el diálogo en Centre International d'etudes Pour La Renovation Du Liberalisme. «Le Colloque Walter Lippmann», p. 461.

56 Centre international d'etudes pour la renovation du liberalisme. «Le Colloque Walter Lippmann», p. 464. 
sistema de precios. Se trata de un paso más en la formación de una política neoliberal, o de una 'agenda' como se dice en el coloquio. A continuación intentaré comentar la traducción política de esta fórmula.

\section{La democracia de la propiedad y la retórica de la urgencia}

Tanto el prólogo escrito con posterioridad a las sesiones para la publicación del congreso como la alocución inaugural, ambas de Louis Rougier, ponen un acento interesante. Se trata de una suerte de llamado de urgencia sobre la necesidad de renovación del liberalismo.

Esta necesidad de renovación se fundamenta en dos causas. Por una parte los problemas endógenos del liberalismo clásico que se ha transformado en un defensor de los privilegios tradicionales. Esta crítica es explícita aunque con ímpetu diverso. Se trata de una llamada dramática que requiere abrir una vía para la democracia en medio de las dos posiciones totalitarias que se ven emerger. Rougier relata en el prólogo la actitud de ánimo de los participantes del siguiente modo:

"Cada uno se sabía en la víspera [ante el umbral] de acontecimientos dramáticos que se estaban por jugar la paz de los pueblos y el destino de Europa; cada uno estaba impaciente por comprometer su parte de responsabilidad en la obra común de recuperación que se imponía. Esto fue, sin solemnidad inoportuna, realmente una asamblea de hombres de buena fe, de hombres buenos y de hombres libres, convencidos de que la opción suprema de la civilización occidental estaba en el retorno del liberalismo bien comprendido, único capaz de garantizar la mejora del nivel de vida de las masas, la paz entre los pueblos [pacificación de los pueblos], tributos [¿deducibles?] del pensamiento y el honor del espíritu humano" ${ }^{57}$.

57 Centre international d'etudes pour la renovation du liberalisme. «Le Colloque Walter Lippmann», p. 410. 
El tono inaugural (mesiánico, en el sentido patológico de la expresión), por una parte y por otro la apelación a una situación de adversidad, por lo demás incontestable, deben llamar nuestra atención sobre la retórica política (incluso propagandística hasta cierto punto) que rodea algunas de las intervenciones del congreso. Particularmente Rougier, Lippman y Marlio. Se trataría de rescatar tanto a las izquierdas y las derechas de las tiranías político-económicas.

El drama moral de nuestra época, es, entonces, la ceguera de los hombres de izquierda que sueñan con una democracia política y con una planificación económica sin comprender que la planificación económica implica el Estado totalitario y que un socialismo liberal es una contradicción en los términos. El drama moral de nuestra época es la ceguera de los hombres de derecha que suspiran de admiración ante los gobiernos totalitarios, mientras que demanda los beneficios de una economía capitalista, sin darse cuenta de que el Estado totalitario devora la fortuna privada, ralentiza y burocratiza todas las formas de la actividad económica de un país, y es por eso que los hombres de izquierda y los hombres de derecha parecen alinearse contra el liberalismo que no busca especialmente el negocio de algunos, porque simplemente busca el negocio de todo el mundo, sin creación de monopolios y privilegios. $Y$ es por esto que los de izquierda y derecha están luchando con un celo común inimaginable por cavar la tumba de las democracias por hacer el juego a las dictaduras ${ }^{58}$.

Finalmente se trata de esto: Democracia contra Dictadura. No hay que perder de vista esta propuesta que resonará de muchas maneras y a través de muchas voces en el siglo XX, especialmente después del fin de la Segunda Guerra Mundial con el ropaje aparente de defensa de la libertad. Se trata de un recurso ideológico

58 Centre international d'etudes pour la renovation du liberalisme. «Le Colloque Walter Lippmann», p. 411. 
en el sentido más antiguo de la expresión, que homologa, ya lo veremos, la democracia con la desregulación de precios, homologa también el keynesianismo con una deriva colectivista que necesariamente conduce a la anulación de la libertad económica. Es la libre concurrencia de transacciones la verdadera garante de toda otra libertad ${ }^{59}$, la tiranía, para Rougier se disfraza de moral económica, en los regímenes intervencionistas.

El libro de Walter Lippmann demuestra de manera concluyente que el socialismo y el fascismo son dos variedades de la misma especie. Proceden uno y otro por la creencia común de que podemos realizar una sociedad más justa, más moral y más próspera, donde la búsqueda egoísta del lucro individual sería sustituida por la satisfacción altruista de las necesidades colectivas de las masas, mediante la sustitución de la economía de mercado, basada en la propiedad individual y en el mecanismo de los precios, [por] una economía planificada, basada en la estatización, parcial o total, de los medios de producción y en las decisiones burocráticas de un órgano central. Sin embargo, lejos de ser más moral y racional, una tal economía no podría ser sino una economía ciega, arbitraria y tiránica, causando un gran despilfarro de bienes económicos y la reducción del nivel de vida de las masas, porque la posibilidad de un cálculo económico consciente le sería denegada ${ }^{60}$.

Es fácil reconocer la reducción argumental desde la salvaguarda de la democracia al reclamo de la fijación de precios. Pero hay aquí

\footnotetext{
59 "La pérdida de la libertad de las transacciones implica la pérdida de todas las otras libertades: la libertad de consumir lo que te gusta, libertad de elección del empleo y la residencia, libertad de reunión y de asociación, libertad de pensamiento y de expresión, porque no se puede tolerar la más mínima sospecha en contra de la excelencia del plan que pretende imponer una escala uniforme de valores, una elección definitiva de los fines y los medios en los ámbitos donde los gustos y las preferencias son básicamente individuales y variados". p. 414.

60 Centre international d'etudes pour la renovation du liberalisme. «Le Colloque Walter Lippmann», p. 413-414.
} 
dos cosas de fondo, pensando en los puntos de divergencia en el coloquio. Primero una posición crítica respecto al liberalismo económico clásico, particularmente al manchesterianismo, y en segundo lugar el reconocimiento tácito de la pauperización de las masas, la imposibilidad del régimen económico de poder realizar una "vida mejor", para la sociedad como conjunto. Este elemento molestará más que un poco a Rueff y Condliffe (y probablemente también a Von Mises y Hayek, que no obstante participan con un papel muy secundario en la discusión de la mesa 4: El liberalismo y la cuestión social). Rueff y Condliffe insistirán en la completa falta de necesidad de tener una política social, y por otra parte mostrarán la paradoja del humanismo liberal de Lippmann que plantea la necesidad de reconocer la condición constructivista de una jurídica que apoye a un mercado no aceptable como natural, y por otra un conservadurismo antropológico-moral. En cualquier caso este desarrollo, que deja a la fijación de precios como el criterio sine qua non de la democracia no puede sino ser curioso. ¿Hasta qué punto se puede ser inconsciente respecto al desplazamiento desde el ámbito económico al político? Porque incluso en el caso de que la libre concurrencia de precios pudiese ser por sí misma el elemento definitorio de una economía liberal. Es evidente que este no es un principio social, es imposible que la fijación de precios constituya un régimen político democrático. No obstante, me parece que estamos ante la gestación de una idea que será clave y muy novedosa para los años posteriores: la gestación de una idea de democracia, que por supuesto no se relaciona con el pueblo o la soberanía popular, pero tampoco con los individuos, como lo hacía el contractualismo o el liberalismo político clásico, sino que es una democracia de la propiedad que tiene como principal fundamento la libertad de transacción. Esto me parece importante pues esta idea de democracia es a la larga la democracia defendida y buscada durante el siglo XX en contra de los totalitarismos que se identifican con economías planificadas o sin libre transacción. Me parece que esta pálida idea de democracia está presente ya en las propuestas finales de este coloquio.

Sólo podemos llegar hasta aquí, aunque sería necesario decir algunas otras cosas, espero haber abierto el deseo de acercarse entonces a las 
discusiones que hay aquí contenidas y de las que he podido dar cuenta muy someramente. Pero hay por supuesto mucho interés económico y político en las actas de este coloquio. Precisamente por lo somero de la exposición, intentaré puntualizar algunas conclusiones finales, para no correr el riesgo de que mis faltas en la exposición no las hayan destacado suficientemente.

\section{Algunas conclusiones}

A) La historia del neoliberalismo es bastante más antigua de lo que parecía en los primeros estudios críticos de la década del 80 . Estas posturas pueden incluso acercarse al siglo de existencia. Por supuesto que esto pone en entredicho la novedad implicada en el adjetivo "neo".

B) El neoliberalismo no es homogéneo, al menos en este primer momento de surgimiento encierra bastantes tensiones y discrepancias, principalmente entre dos grupos. Un primer grupo de quienes admiten los errores del manchesterianismo e incluso lo consideran responsable del descrédito del liberalismo económico, y un segundo grupo, más bien renuente a aceptar la crítica al manchesterianismo, aunque igual de convencido que el primer grupo en el sentido de la necesidad de renovar el liberalismo. En el primer grupo se encuentran las bases del ordoliberalismo alemán, mientras que en el segundo grupo estarían las bases de la escuela de Chicago.

C) El coloquio Walter Lippmann tiene un valor que sobrepasa el de la efeméride histórica; pues en él se nos muestra precisamente la existencia de un debate heterogéneo que tenderá a perderse en la sociedad de Mont Pèlerin. Por otra parte, la divergencia de posturas de 1938 hasta cierto punto puede iluminar algunos de los debates actuales en la medida que identifica variaciones dentro del discurso neoliberal.

D) Algunas de las posturas que hoy parecen resistir o ser alternativas al neoliberalismo, como las que abogan por la intervención estatal en ciertos ámbitos estabilizadores de la economía (monopolios, fondos 
de estabilización, rescates y ahorro estructural) o mitigadores de los efectos adversos inmediatos sobre la población (especialmente seguro de desempleo, pero también otro tipo de prestaciones sociales mitigantes o reguladoras) en realidad expresan una versión neoliberal más moderada que ya estaba presente en las posturas de 1938 y que tenderá a solidificarse con el tiempo en la vertiente alemana u ordoliberal.

E) Se puede observar que las ideas sociales del ordoliberalismo presentes en las discursos del coloquio Lippmann son las que después han configurado la llamada economía social de mercado, y que hasta cierto punto hoy se confunden con la idea de "social democracia" en el acervo común y la opinión pública, al punto que no es poco frecuente que cuando se habla de social democracia se refiera a los postulados esenciales de la economía social de mercado que ya en 1938 se expresaba como germen en las posturas de un grupo importante de pensadores neoliberales.

F) Ya desde 1938 se observa una clara intención política en los intelectuales neoliberales, especialmente en sus posturas frente al Estado como sostenedor de los mecanismos del mercado y la reducción de la idea de democracia a un sistema de gobierno que posibilite la libre fijación de precios. Por supuesto la participación posterior de gran parte de los asistentes al coloquio Lippmann en puestos políticos apoya esta idea.

G) La estrategia de encerrar toda experiencia política posible a dos opciones antagónicas y excluyentes como democracia y totalitarismo, homogeneiza como democracia toda oposición al totalitarismo, como si todo sistema de gobierno no totalitario fuera por conclusión democrático; al mismo tiempo que se define al totalitarismo como coacción económica, en particular, como dirigismo e intervención sobre la libre fijación de precios. Tenemos como resultado una idea jibarizada de democracia, una democracia de la propiedad o el gobierno para la libre competencia económica. 


\section{Bibliografía}

Alvarez-Uría, Fernando. «Karl Polanyi y sus contemporáneos. Sobre la subordinación de los mercados a los valores de la civilización y de la libertad». ENCRUCIJADAS. Revista Crítica de Ciencias Sociales, N7, 2014.

Anderson, Perry. «Historia y lecciones de neoliberalismo» En Hourtart, François; Polet, François. El otro Davos: globalización de resistencias y de luchas. Madrid, Plaza y Valdés, 2001.

Audier, Serge. Le colloque Lippmann. Aux origines de "neo-libéralisme". Paris, Le bord l'eau, 2012.

Baudin, Louis. L'aube d'un nouveau libéralisme. Paris, Librairie de Médicis, 1953.

Casilda Béjar, Ramón. «América Latina y el Consenso de Washington». Boletín Económico de ICE n² 2803 del 26 de abril al 2 de mayo de 2004.

Denord, François. «Aux origines de néolibéralisme en France; Louis Rougier et le colloque Walter Lippmann de 1938». En Le Mouvement social, 2001, № 195.

Escalante Gonzalbo, Fernando. Historia mínima del neoliberalismo. Colegío de México, México D.F., 2015. Centre international d'études pour la rénovation du libéralisme. «Le Colloque Walter Lippmann». En Audier, Serge. Le colloque Lippmann. Aux origines de "neo-libéralisme". Paris, Le bord I'eau, 2012.

Foucault, Michel. Naissance de la biopolitique. Cours au Collège de France 1979-1980. Paris, Seuil/Gallimard, 2004.

Ghersi, Enrique. «El mito del neoliberalismo». Estudios Públicos, 95 (invierno 2004).

Harvey, David. «¿ls This Really the End of Neoliberalism?». En Counterpounch March, 13, 2009. Disponible en http://www.counterpunch. org/2009/03/13/is-this-really-the-end-of-neoliberalism/.

Harvey, David. A brief history of neoliberalism. New York, Oxford University Press, 2005.

Hayek, Friedrich. «The Atavism of SociaL Justice». En Hayek, Friedrich. New studies in philosophy, politics, economics and the history of ideas. London, Routledge, 1996.

Hayek, Friedrich. «The Principles Of A Liberal Social Order» En Hayek, Friedrich. Studies In Philosophy, Politics And Economics. London, Routledge, 1967.

Hayek, Friedrich. Camino de servidumbre. Madrid: Alianza, 1985. 
Kuczynski, Pedro. «Explicando el contexto». en Kuczynski, Pedro; Williamson John (eds.), Después del Consenso de Washington. Relanzando el crecimiento y las reformas en América Latina. Lima, Universidad Peruana de Ciencias Aplicadas, 2003.

Laval, Christian; Dardot, Pierre. La nouvelle raison du monde. Paris, La Découverte, 2010.

Lippmann, Walter. The Good Society. Little, Brown \& Co. Boston, 1937. En francés ver Lippmann, Walter. La cité libre. Librairie de Médicis, Paris, 1938. En castellano, ver Lippmann, Walter. Retorno a la libertad, México, Unión Tipográfica Hispanoamericana, 1940.

López, Pablo. «Sigue cierta algarabía. Foucault, el neoliberalismo y nosotros». En Castro, Rodrigo; Salinas Adán. La actualidad de Michel Foucault. Madrid, Escolar y Mayo Editores, 2016.

Mirowski, Philip; Plehwe, Dieter. The Road From Mont Pèlerin. CambridgeLondon, Harvard University Press, 2009.

Mises, Ludwig von. Die Gemeinwirtschaft. Untersuchungen über den Sozialismus. Verlag von Gustav Fischer, Jena, 1922. Disponible en http://docs.mises. de/Mises/Mises_Gemeinwirtschaft.pdf

Mises, Ludwig von. Human action. A Treatise on Economics. Alabama, Ludwig Von Mises Institute, 1998.

Mises, Ludwig von. Liberalismus. Jena, Verlag, 1927. Hay traducción castellana en 1975 bajo el título Liberalismo y editada por Unión Editorial, reeditada por Planeta en 1994. En inglés, Mises, Ludwig von. Liberalism. Princeton, Van Nostran, 1978.

Plehwe, Dieter. «Introduction». En Mirowski, Philip; Plehwe, Dieter. The Road From Mont Pèlerin. Cambridge-London, Harvard University Press, 2009, p. 13.

Salinas, Adán. Vidas precarias y Ciclo Vital. Escrituras aneconómicas. Vol. V, 2014.

Salinas, Adán. «El hombre empresa como proyecto ético-político. Lecturas de Michel Foucault". En Hermenéutica intercultural. 18-19, 2010, pp. 95-139.

Salinas, Adán. La semántica biopolítica. Viña del Mar, Cenaltes Ediciones, 2014.

Walpen, Bernhard. «Auf dem Pilgerberg oder: Dialektik der Freiheit. Eine kurze Geschichte des Neoliberalismus» En Denknetz Jahrbuch 2005, pp. 210-218.

Williamson, John. «Revisión del consenso de Washington». En Emerij, Luis; Núñez Del Arco, José. El desarrollo económico y social en los albores del siglo XXI. Washington, BID, 1998. 
Williamson, John. «What Washington Means by Policy Reform». En Williamson, John (ed). Latin American Adjustment: How Much Has Happened? Washington, Institute for International Economics, 1990. 